\title{
Recursos audiovisuais nas aulas de espanhol como língua estrangeira: uma experiência realizada com alunos do IFPB-Cajazeiras.
}

\author{
Larissa Pinheiro Xavier \\ Instituto Federal de Educação, Ciência e Tecnologia da Paraíba - IFPB
}

\begin{abstract}
Resumo
O trabalho relata atividades com o uso de filmes que fizeram parte de experiências realizadas, durante o ano de 2016, na disciplina de Espanhol II, com alunos dos cursos integrados no Instituto de Educação, Ciência e Tecnologia do IFPB, campus Cajazeiras. $\mathrm{O}$ uso de recursos audiovisuais como filmes tem como objetivo principal a aprendizagem da Língua Espanhola em seus mais diversos aspectos, sejam eles culturais, gramaticais, linguísticos, sintáticos, sociais e históricos.

Palavras-chave: Cinema; Ensino; Prática; Língua Espanhola.
\end{abstract}

\begin{abstract}
The paper reports activities with the use of movies that were part of the teachinglearning experiences during 2016, in the subject 'Spanish II', with students from the integrated courses in Instituto Federal de Educação, Ciência e Tecnologia da Paraiba, campus Cajazeiras. The use of audiovisual resources such as movies has as main goal the learning of the Spanish Language in its many aspects, namely: cultural, grammatical, linguistic, syntactic, social and historical.
\end{abstract}

Keywords: Movies. Teaching. Practice. Spanish Language.

\section{INTRODUÇÃO}

Pesquisas recentes apontam que o ensino de Espanhol como LE no Ensino Médio, principalmente considerando aqui as turmas dos cursos tecnológicos do campus Cajazeiras, do IFPB, apresentou dificuldades quando se trata de aperfeiçoamento da compreensão oral. O uso excessivo da gramática (livro didático) torna as aulas enfadonhas, com atividades repetitivas, pautadas em uma prática tradicional, e isso ocasiona um baixo rendimento no desenvolvimento não só oral, mas cognitivo, auditivo, lexical, linguístico, além do conhecimento de mundo acerca da língua em questão. De acordo com os PCN (Ensino Médio),

Em lugar de capacitar o aluno a falar, ler e escrever em um novo idioma, as aulas de Línguas Estrangeiras Modernas nas escolas de nível médio acabaram por assumir uma feição monótona e repetitiva que, muitas vezes, chega a desmotivar professores e alunos, ao mesmo tempo em que deixa de valorizar conteúdos relevantes à formação educacional dos alunos (BRASIL, 2000, p. 25). 
Com isso, existe uma necessidade de mudança no planejamento da disciplina para que seja possível um melhor desenvolvimento das aulas. Um dos recursos que podem ser incorporados às aulas é a utilização de filmes, pois estes podem se transformar na própria aula, com todos os recursos disponibilizados e trabalhados.

Com base nessa premissa, este trabalho tem como escopo tratar das práticas de sala de aula utilizando o recurso dos filmes como maneira de melhorar a aprendizagem e o desenvolvimento dos alunos na disciplina de língua espanhola. As práticas foram realizadas com alunos dos Cursos Integrados nas áreas de Edificações, Informática e Eletromecânica, no Instituto Federal de Educação, Ciência e Tecnologia da Paraíba, Campus Cajazeiras. Algumas reflexões teóricas levaram em consideração autores como SERRANO (2010), ALMEIDA FILHO (2007) E NAPOLITANO (2003), que abordam a temática de recursos audiovisuais na sala de aula, bem como teorias sobre o Ensino de Língua Estrangeira (LE) no Ensino Médio.

\section{REFLEXÕES TEÓRICAS}

São vários os estudos em que se aborda uma reflexão acerca dos novos rumos para o ensino de língua estrangeira que vão além do tradicional. Como princípio social e dinâmico, essa reflexão não se restringe a uma visão sistemática e estrutural do código linguístico. É heterogênea, rompe os muros da escola, supera os conteúdos, muitas vezes abordados tão superficialmente nos livros didáticos.

Diante disso, sente-se a necessidade de que o ensino de idiomas não se paute apenas no estudo estrutural da língua, mas também nos aspectos culturais, sociais, históricos, linguísticos, com o intuito de desenvolver no aprendiz o senso crítico, a competência linguística (aquisição da língua, desenvolvimento da linguagem e aprendizado da gramática normativa), além da competência discursiva, quando o estudante se sensibiliza para os diferentes tipos de discursos e para as diferenças dos códigos orais e escritos.

Dessa maneira, o desenvolvimento científico e tecnológico de anos recentes possibilitou aos docentes o uso de ferramentas que os auxiliam consideravelmente no aprimoramento de estratégias pedagógicas como o uso de recursos audiovisuais, segundo Cruz, Gama \& Souza (2006). Nesse contexto, o uso de filmes em sala de aula, por exemplo, é relevante, uma vez que 
esse tipo de material torna-se didático, quando é trabalhado para esse fim e não como simples passatempo, surgindo como uma alternativa viável para o ensino/aprendizagem de Espanhol como Língua Estrangeira.

Levando em consideração o Art. 36 da LDB, o currículo do Ensino Médio deverá adotar “metodologias de ensino e avaliação que estimulem a iniciativa dos alunos" (LDB, 2010, p.29). Dessa forma, recorrer ao uso de filmes com finalidade educativa, usados como conteúdo que formará a aula, ocasiona aprendizado, pois essa perspectiva é corroborada pelas Orientações Curriculares para o Ensino Médio (OCEM), quando diz que o material didático do qual o professor dispõe engloba os livros didáticos, os textos, os vídeos, as músicas, os chats, os documentários, as gramáticas, os dicionários, entre outros. As orientações afirmam ainda que o planejamento adequado considera o curso como um todo, incorporando alguns desses recursos de maneira harmônica, pois se ater a apenas um recurso não contempla todos os aspectos relacionados à língua em estudo.

Ademais, o objetivo de proporcionar aos alunos oportunidades de conhecimento e aprendizagem da língua sejam elas orais e/ou escritas, faz do recurso audiovisual um suporte significativo para abordar aspectos linguísticos e culturais, pois os diálogos, o cenário, a temática são construídos pelos falantes nativos da língua-alvo. O filme se torna vantajoso pelo fato de ser uma mostra autêntica produzida sem manipulações para fins didáticos.

Segundo Serrano (2010, p. 25), o cinema é uma metáfora do mundo que permitirá “apresentar conteúdos culturais e socioculturais na aula. O cinema ajudará a conhecer (e a destruir) estereótipos da cultura cuja língua é estudo de aprendizagem ${ }^{1}$ ”. O uso do filme nas aulas de E/LE ajuda a compreender a trama do filme partindo do conteúdo cultural presente, tal como Serrano (2010) propõe. As atividades elaboradas com esse recurso têm a finalidade de criar uma visão positiva da diversidade cultural partindo do reconhecimento próprio do aluno e apresentando-lhe outras sociedades. É importante retratar a diversidade linguística e cultural presente na Língua Espanhola (língua oficial da Espanha e de diversos países da América Latina).

Os filmes são uma representação da linguagem oral coloquial e, portanto, na escolha do material para o uso em classe, é fundamental ter em vista o direcionamento linguístico que as

\footnotetext{
1 "Presentar contenidos culturales y socioculturales en el aula. El cine ayudará a conocer (y a destruir) estereótipos de la cultura cuya lengua es estudio de aprendizaje" (SERRANO, 2010, p. 25).
} 
obras representarão. Os filmes são mostras de uso da linguagem e é partindo desse pressuposto que as aulas devem ser elaboradas. A exposição da fala dos personagens tem a função de expressar o uso coloquial, real, cotidiano do Espanhol. Para entender melhor, Almeida Filho (2007) afirma que:

\begin{abstract}
A aula de língua estrangeira como um todo pode possibilitar ao aluno não só a sistematização de um novo código linguístico que o ajudará a se conscientizar do seu próprio, mas também a chance de ocasionalmente se transportar para dentro de outros lugares, outras situações e pessoas. Esses clarões culturais conseguem, às vezes, marcar nossa percepção e memória de maneira indelével e para sempre (ALMEIDA FILHO, 2007, p. 28).
\end{abstract}

Outro teórico que recomenda o uso do cinema na sala de aula para o ensino de línguas estrangeiras é Napolitano (2003). Ele aponta em seu livro, principalmente, o caráter lúdico desse recurso, pois possibilita o aprendizado da língua de forma divertida e envolvente (p. 44). Completa dizendo que pelo fato do filme ter como propósito o entretenimento do público, isso auxilia na motivação para o aprendizado da língua.

É com base nessas reflexões que o filme insere-se como meio de aprendizagem e deve existir para novos conhecimentos de códigos linguísticos, para se adequarem ao ensino e ao desenvolvimento da habilidade de diversas competências nas de E/LE.

\title{
A PRÁTICA
}

A proposta aconteceu inicialmente com a turma Espanhol II, e a atividade foi dividida em seis aulas. As aulas acontecem duas vezes por semana com duração de cem minutos. O tema foi selecionado a partir de uma das unidades apresentada no livro didático adotado pela Instituição, chamado "Enlaces 2, Español para jóvenes brasileños", da Editora Macmillan (2013). Na unidade dois do presente livro, o conteúdo gramatical apresenta os tempos verbais no passado sob o título cultural "Memórias del silencio". Essa temática tem como foco a abordagem da Ditadura Militar que aconteceu em alguns países da América Latina. Textos sobre a Ditadura no Chile, citando o presidente Salvador Allende, e também texto de compreensão leitora abordando a história das "Madres de la plaza de Mayo", ocorrida em Buenos Aires, na mesma época, introduziram o conteúdo desta unidade. 
Na primeira aula, por meio de um prévio planejamento, foi trabalhado inicialmente o conhecimento de mundo dos alunos, antes de chegar de fato ao conteúdo gramatical. Eles imaginaram a que se referiam as fotos (imagens 1 e 2) apresentadas na capa da unidade sob o título acima citado. Eram figuras que remetiam ao período ditatorial com imagens das mães e seus panos brancos na cabeça na praça de Maio, em Buenos Aires. Outra imagem apresentava militares sérios de braços cruzados e na outra foto havia soldados com cassetetes nas mãos segurando os braços e as pernas de um cidadão caído no chão.

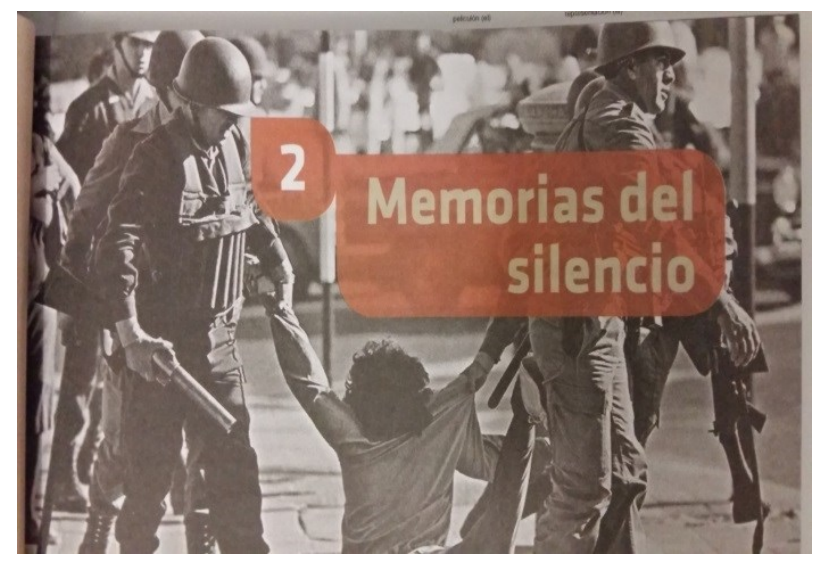

Imagem 1 - Imagens da ditadura

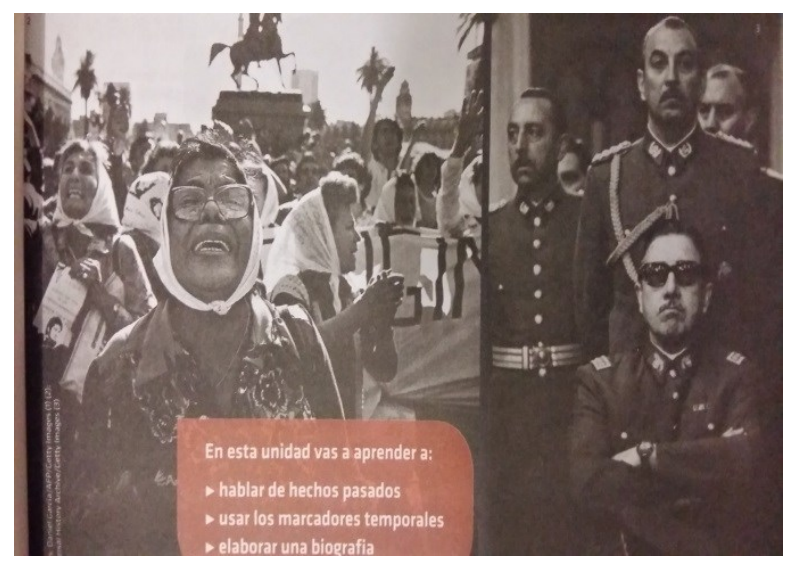

Imagem 2 - Imagens da ditadura

Com essas imagens, foram feitas perguntas sobre elas, tentando fazer com que os alunos as compreendessem e falassem um pouco sobre o conhecimento deles acerca do que é uma ditadura e de suas implicações na sociedade, fazendo alusão também à Ditadura no Brasil. Em seguida, foram respondidas a questões de compreensão de texto e auditiva do livro, sempre discutindo com eles a temática. Após isso, foi apresentado um documentário em espanhol com legendas sobre as "Madres de la plaza de Mayo", com uma pequena discussão ao final.

Nesse debate, os alunos ressaltaram imagens que chamaram atenção, como os atos de repressão e violência, além da compreensão que tiveram sobre a importância da luta das pessoas pelos direitos humanos e civis. Isso vai ao encontro do que Serrano (2010) propôs no seu estudo, a compreensão da trama do filme e de poder conhecer um pouco sobre a realidade latinoamericana, como ocorreu na ditadura chinela.

$\mathrm{Na}$ segunda e na terceira aulas, foi apresentado o filme chileno-espanhol, Machuca (2004), do diretor Andrés Wood. O filme conta a história do Chile no período de 1973. Gonzalo 
Infante e Pedro Machuca são dois garotos de onze anos que vivem em Santiago. O primeiro, num bairro de classe média alta, o segundo, num humilde povoado próximo. Dois mundos separados por uma muralha invisível que alguns sonham em derrubar na intenção de construir uma sociedade mais justa. Um desses sonhadores é o padre McEnroe, diretor de um colégio particular. Com a política educacional de Salvador Allende, ele decide fazer uma integração entre esses dois universos, abrindo as portas do colégio para os filhos das famílias do povoado. É assim que Pedro Machuca vai parar na mesma sala de Gonzalo Infante, nascendo daí uma amizade plena de descobertas e surpresas, apesar do clima de enfrentamento que vive a sociedade chilena na violenta transição de Allende para Pinochet.

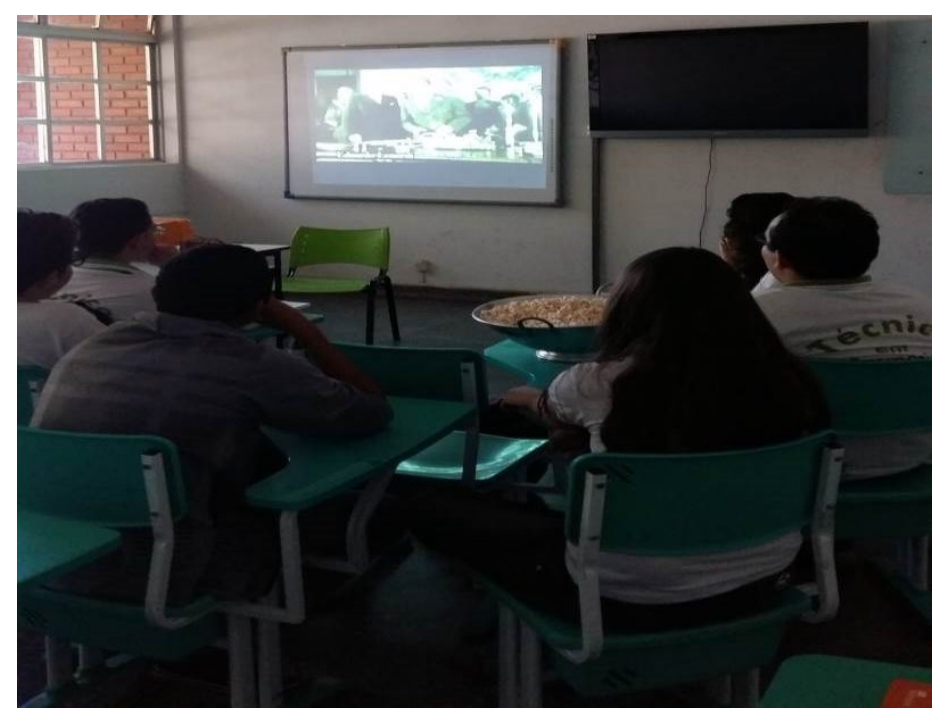

Imagem 3 - Alunos assistindo ao documentário "Madres de la plaza de Mayo".

A quarta aula foi iniciada com uma atividade escrita que compreendia questões objetivas e subjetivas sobre o filme: identificar os personagens principais (nomes e características); com qual deles cada um se identificou mais e por quê; onde acontece a história, ano e contexto; questão de múltipla escolha sobre uma determinada cena do filme; outra sobre se eles conhecem realidades similares hoje em dia e quais; e a última era para eles comentarem sobre uma parte do filme que lhes causou mais impressão ou reflexão. As respostas foram corrigidas oralmente, sempre na busca de reflexões e de discussões sobre o que os aprendizes conseguiram compreender e assimilar do filme.

$\mathrm{Na}$ quinta aula, foi ministrada uma atividade avaliativa oral em forma de seminário. Cada aluno, por meio de um prévio sorteio, ficou com um país que vivenciou a Ditadura Militar 
(Chile, Uruguai, Paraguai, Argentina). Estipulou-se vinte minutos para cada um, e eles podiam usar recursos audiovisuais para a apresentação (Figs 4 -7). A partir disso, foi avaliada a oralidade, o domínio do conteúdo e o material utilizado. Nesse seminário, eles apresentaram, através de power point, o significado de Ditadura, como ela aconteceu em cada país e suas consequências, os principais envolvidos nos golpes militares, a realidade social e econômica da população, a questão dos direitos humanos, dentre outros.

Além disso, também expuseram fotos e vídeos relacionados com o referido período. Nos vídeos, havia entrevistas com ex-exilados, com cidadãos que vivenciaram a ditadura e imagens reais que mostraram os toques de recolher e bombardeios, e narrações explicando fatos ocorridos, como de pessoas desaparecidas. Finalizaram com informações sobre o término do período ditatorial, as sequelas dessa repressão nos dias atuais, as personalidades que foram influentes durante o período e fatos curiosos que eles quiseram mostrar.

Aliamos a teoria proposta pelos PCNs como por Almeida Filho (2007) à prática de pesquisa, de compreensão leitura e cultural das atividades aqui propostas, pois ambos discutem que a aprendizagem deve partir do aluno, da vivência de situações e contextos reais de uso da língua.

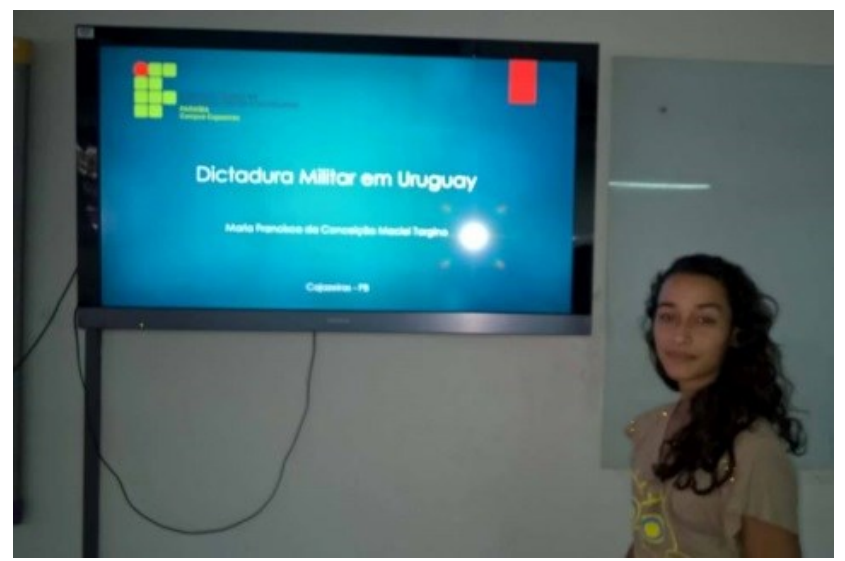

Imagem 4: Aluna apresentando sobre a ditadura no Uruguai

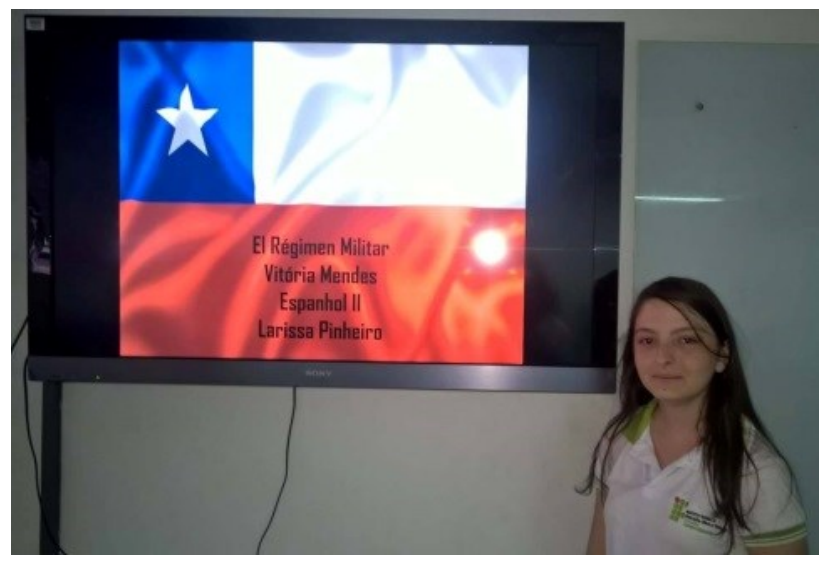

Imagem 5: Aluna apresentando sobre a ditadura no Chile 


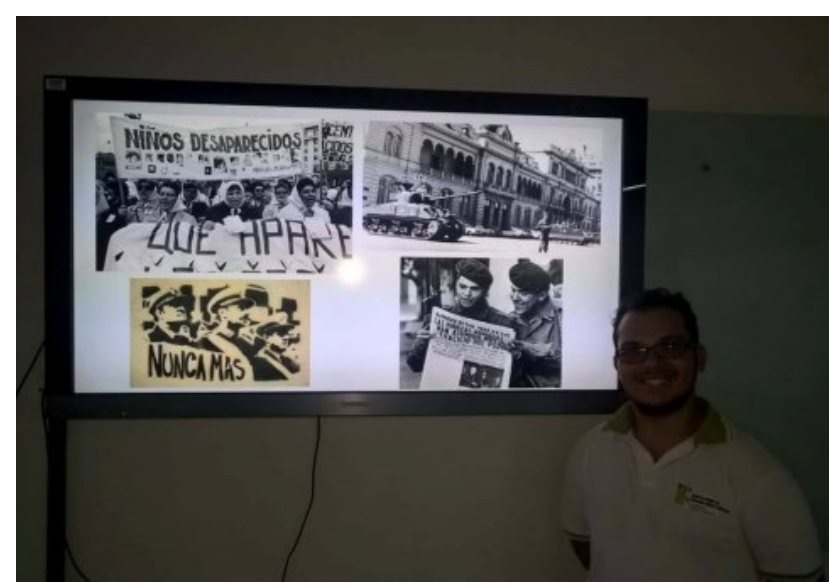

Imagem 6: Aluno apresentando sobre a ditadura na Argentina

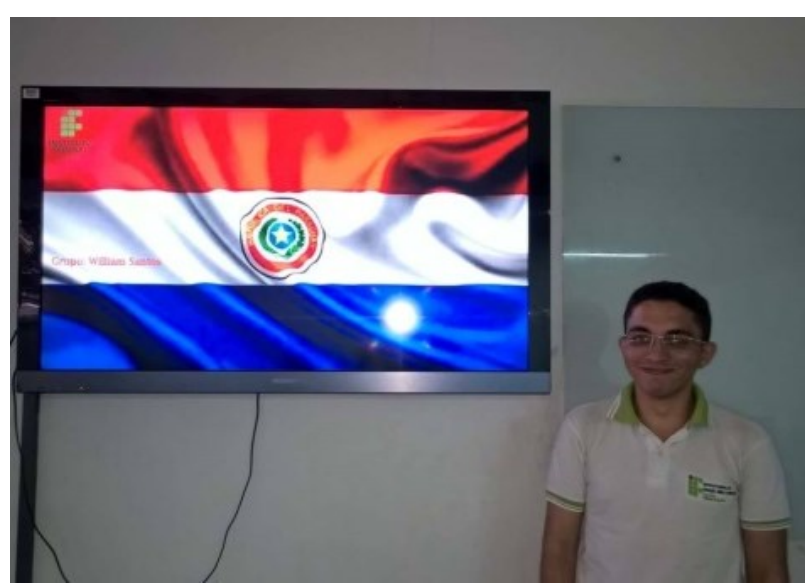

Imagem 7: Aluno apresentando sobre a ditadura no Paraguai

Na sexta aula, foi abordado o conteúdo gramatical com os verbos no tempo passado. Textos com o uso real dos verbos foram lidos e, em sequência, feita a compreensão leitora, sempre estimulando os alunos a refletirem sobre a temática do projeto. Em seguida, foram abordadas as questões gramaticais (regras e usos) de alguns verbos regulares e irregulares. A atividade prática buscou, assim, trabalhar essas questões discutidas para que os alunos pudessem aprender a real utilização dos três tempos verbais trabalhados (pretéritos perfecto compuesto, indefinido e imperfecto). Para melhor assimilação do conteúdo, foram passados também exercícios para prática em casa.

Na última aula relativa ao projeto, buscou-se junto à turma a elaboração de uma avaliação de autoconhecimento acerca de tudo o que havia sido visto e também para avaliar o que eles haviam achado do projeto (pontos positivos e negativos).

Dentre as respostas obtidas, os alunos, de uma forma geral, informaram que aprenderam sobre as razões da Ditadura e os sofrimentos causados por ela nesses países latino- americanos, e falaram da violência e das mortes.

Eles também gostaram bastante de aprender um pouco sobre a temática e, mais especificamente, das pesquisas que realizaram para poderem apresentar os trabalhos em sala. Um aluno afirmou: "me gustó conocer un poco la historia de los países que fueron presentados". Outro já disse "me gustó mucho la película Machuca y ver que las personas de clase baja fueron las que más sufrieron con el periodo". Vemos a perspectiva abordada por Napolitano (2003) no 
que tange a umas das características do uso do filme na sala de aula, ou seja, o aprendizado se deu de maneira envolvente.

\section{CONSIDERAÇÕES FINAIS}

Esse trabalho teve como propósito contribuir para um melhor aproveitamento dos conteúdos linguísticos da Língua Espanhola, por meio de abordagens mais ricas e abrangentes que ultrapassem os livros didáticos e não a detenção só de conteúdos gramaticais e exercícios do livro.

Diante da realidade do ensino de ELE, procurou-se alcançar uma melhoria no aproveitamento das aulas, fazendo oposição aos métodos tradicionais normativos, que recorrem demasiadamente às regras gramaticais e, com isso, ocorre das aulas tornarem-se enfadonhas por grande parte dos alunos, o qual gera baixo rendimento dos conteúdos.

Romper, portanto, os muros da sala de aula e fazer com que os alunos ampliem seus conhecimentos através de assuntos culturais, políticos, sociais e históricos foram fatores determinantes para o uso da ferramenta áudio visual nas aulas de Espanhol. O filme Machuca possibilitou a abertura de reflexões acerca desses conhecimentos e de estudos mais aprofundados sobre alguns dos países da América do Sul que passaram por regimes militares.

A experiência mostrou-se bastante positiva por trabalhar com os aprendizes todas as competências necessárias para a aprendizagem de uma língua estrangeira. Isso mostra que deve sempre haver um bom planejamento para diversificar materiais, conteúdos e atividades para os alunos aprenderem.

O uso de filmes, por exemplo, pode abordar diversos conteúdos em simultaneidade com atividades comunicativas. Acredita-se que esse recurso, como outros similares, possibilita e possibilitará aos alunos o aprendizado das variações linguísticas e cognitivas existentes na língua, que permitem uma exploração vasta do mundo hispano-americano.

Destarte, os objetivos aqui apresentados foram atingidos, uma vez que os alunos interagiram, refletiram, contribuíram com seus conhecimentos de mundo e apresentaram resultados positivos nas apresentações das atividades orais com base nos assuntos passados e refletidos durante o projeto. 


\section{REFERÊNCIAS}

ALMEIDA FILHO, J. C. P. Dimensões comunicativas no ensino de línguas. Campinas - SP. Pontes Editores, $4^{\mathrm{a}}$ edição, 2007.

BRASIL, Lei das Diretrizes e Bases da Educação Nacional -LDB, 2010.

BRASIL, OCEM: Orientações Curriculares para o Ensino Médio. Linguagens, códigos e suas tecnologias. Volume 1. Secretaria de Educação Básica. - Brasília: Ministério da Educação, 2006.

BRASIL, Parâmetros Curriculares Nacionais: Ensino Médio. Brasília. Ministério da Educação, 200.

CRUZ, M.L.O.B; SOUZA, F.M; GAMA, A.P.F. O cinema no aperfeiçoamento das competências de línguas (materna e estrangeira). In. Prógrad UNESP (Org.) Livro eletrônico dos núcleos de ensino da UNESP. São Paulo: Cultura Acadêmica Editora, 2007, v., p. 487-499.

NAPOLITANO, M. Como usar o cinema na sala de aula. São Paulo: Contexto, 2003.

SERRANO, C. V. EI uso de cortometraje en el aula de ELE como herramienta para elaprendizajedel léxico. Memoria de Master lingüística aplicada en ELE. Universidad de Jaén. Fundación Universitaria Iberoamericana (FUNIBER), 2010, p. 21-40.

\section{REFERÊNCIAS FILMOGRÁFICAS}

TV PÚBLICA ARGENTINA. Madres de la plaza de mayo- la historia.Capitulo 1 e 2. 2015. Disponível em $<$ https://www.youtube.com/watch?v=NDJP9vRUX20 $>$. Acesso 25 de ago de 2016.

TV PÚBLICA ARGENTINA. Madres de la plaza de mayo - la historia. Capitulo2. 2015. Disponível em $<$ https://www.youtube.com/watch?v=iB7SCObGtRI $>$. Acesso 25 de ago de 2016.

WOOD, A (dir.). Machuca. Chile-Espanha, 2004, 2h 1m.

\section{A AUTORA}

Larissa Pinheiro Xavier é mestre em Letras/Literatura Comparada pela Universidade Federal do Ceará. Graduada em Letras/Espanhol pela Universidade Estadual do Ceará. Há quatro anos faz parte do corpo docente efetivo do Instituto Federal de Educação, Ciência e Tecnologia da Paraíba, campus Cajazeiras. Desenvolve trabalhos na área de ensino e extensão na disciplina de 
Língua Espanhola. É coordenadora do Grupo de Pesquisa Ensino e Aprendizagem de Línguas e do Núcleo de Assuntos Internacionais - NAI, da referida instituição.

\section{E-mail: larissapxavier@yahoo.com.br}

